\title{
A POSSIBILIDADE DE RECONHECIMENTO DA QUALIFICADORA DO FEMINICÍDIO EM FACE DA PRESENÇA DE OUTRA QUALIFICADORA SUBJETIVA NO CRIME DE HOMICÍDIO
}

\section{THE POSSIBILITY OF RECOGNITION OF THE FEMINIST QUALIFIER IN FACE OF THE PRESENCE OF ANOTHER SUBJECTIVE QUALIFIER IN THE MURDER CRIME}

\section{Estér Corrêa Coelho}

Resumo: $\mathrm{O}$ feminicídio é um novo tipo de homicídio qualificado, previsto pela Lei n. 13.104/2015, trata-se de um novo mecanismo no combate à violência doméstica contra a mulher, com o intuito de impor uma sanção mais severa ao homicídio praticado contra a mulher por razão da condição do sexo feminino no cenário de violência doméstica e familiar, e nas situações de menosprezo e discriminação à condição de ser mulher. Anteriormente a esta aludida lei não existia uma punição específica para o homicídio que praticado contra a mulher por razões que envolvessem o sexo feminino, assim, o feminicídio era penalizado de forma geral como simples homicídio qualificado, usualmente enquadrado como motivo torpe ou fútil, previstos no art. $121, \S 2^{\circ}$, incisos I e II. Ainda, acerca de sua natureza qualificadora, trouxe a relevante controvérsia sobre sua natureza ser objetiva ou subjetiva, porém predomina-se a corrente de que a qualificadora do feminicídio é de natureza subjetiva. Isto porque tal crime ocorre exclusivamente pela motivação do delito, que são consideradas subjetivas, pois não caberia falar em natureza objetiva por não dizer respeito ao modo ou meio de execução do crime. O objetivo desta pesquisa tem por escopo em compreender a possibilidade do reconhecimento da qualificadora de feminicídio como sendo de natureza

1 Bacharela em Direito pela Universidade Anhanguera-Kroton em Santa Catarina, aluna do módulo Conteúdos Jurídicos e pós-graduanda em Direito Público pela Escola Superior de Magistratura do Estado de Santa Catarina (Esmesc). E-mail: estercorreacoelho@gmail.com. 
subjetiva, cumulada com outra qualificadora também subjetiva (motivo torpe/fútil), permitindo punições mais rigorosas para crimes cometidos nessas circunstâncias.

Palavras-chave: Código penal. Homicídio qualificado. Feminicídio. Lei n. 13.104/2015. Natureza qualificadora. Qualificadora subjetiva. Qualificadora objetiva.

ABSTRACT: Femicide is a new type of qualified homicide, provided for in Law n. 13.104/2015. It is a new mechanism to combat domestic violence against women, with the aim of imposing a more severe sanction on the homicide committed against women by the reason for the condition of the female sex in the scenario of domestic and family violence, and in the situations of disparagement and discrimination to the condition of being a woman. Previously to this aforementioned law there was no specific punishment for the homicide committed against the woman for reasons involving the female sex, thus, feminicide was generally penalized as a simple qualified homicide usually framed as an awkward or futile motive, provided for in art. 121, § 2, items I and II. Still, about its qualifying nature, it has brought the relevant controversy over its nature to be objective or subjective, but the current that the qualifier of feminicide is of a subjective nature predominates. This is because such a crime occurs exclusively because of the motivation of the crime, which are considered subjective, because it would not be necessary to speak of an objective nature because it does not concern the way or means of execution of the crime. The purpose of this research is to understand the possibility of recognition of the feminicide qualifier as being of a subjective nature, combined with another subjective qualifier (awkward / futile motive), allowing stricter punishments for crimes committed in these circumstances.

KEYWORDS: Criminal Code. Qualified Homicide. Feminicide. Law 13.104/2015. Nature Qualifier. Subjective Qualifier. Objective Qualifier.

\section{INTRODUÇÃO}

A violência contra a mulher, por razões de gênero, é uma das mais graves formas de agressão ou violação, pois lesa a honra, o amor próprio, a autoestima e seus direitos fundamentais; trata-se, portanto, de um crime que deixa mais do que marcas físicas, atingindo a própria dignidade da mulher, como ser humano e cidadã, que merece um tratamento igualitário, urbano e respeitoso por sua própria condição de mulher.

$\mathrm{Na}$ data de 09 de março de 2015 foi sancionada a Lei $\mathrm{n}$. 13.104 (BRASIL, 2015), trazendo mudanças significativas ao 
art. $121, \S 2^{\circ}$ do Código Penal, incluindo em seu rol de qualificadoras o feminicídio, qual seja o homicídio contra a mulher por razões da condição de sexo feminino, quando o crime envolver violência doméstica e familiar e/ou menosprezo ou discriminação à condição de mulher, a fim de diminuir a ocorrência de homicídios de mulheres no país por questões de gênero.

Para tanto, nos crimes cometidos com vítima mulher antes da inserção da nova qualificadora, a legislação pátria anterior a Lei n. 13.104/15 não se mostrava eficaz em tratar do delito violência contra a mulher. Assim, por não existir nenhuma punição em especial, eram enquadrados à época para condenação do sujeito ativo que praticasse o delito contra a vítima mulher por razões de gênero, o motivo torpe ou fútil, ambos previstos no art. 121, incisos I e II do Código Penal.

A nova circunstância qualificadora do feminicídio, traz grande controvérsia acerca de sua natureza, ou seja, se possui característica qualificadora objetiva ou subjetiva, ainda, se há possibilidade do convívio entre duas qualificadoras subjetivas em concurso com a qualificadora do feminicídio; há os que defendem o feminicídio ser de natureza objetiva e há os que defendem ser de natureza subjetiva, por isso faz-se explanar sobre ambos os lados. A partir disso a doutrina e a jurisprudência passarão a debater acerca da natureza do crime de feminicídio, trazendo à baila diferentes doutrinas e julgados para sanar a presente questão.

Assim, com presente artigo pretende-se fundamentar justamente na existência ainda hoje da violência contra as mulheres, em suas mais variadas formas. O tipo qualificador de feminicídio é a mais cruel das formas de violência contra a mulher e apesar de ser uma nomenclatura relativamente nova, este crime ocorre há muitos anos nas sociedades como forma de domínio masculino, o que de certo mudou com a vigência 
da Lei no ano de 2015.

Como forma de inverter está situação, os elementos que eram tipificados anteriores à Lei acima mencionada, trazem como discussão para o presente trabalho a possibilidade do reconhecimento da qualificadora do inciso VI do art. 121 do CP (feminicídio), de natureza subjetiva, sendo possível concurso com outra qualificadora subjetiva (motivo torpe/fútil), visando a proteção à mulher, o que permite que crimes cometidos nessas circunstâncias sejam punidos de forma rigorosa. É o que será discutido e visto nos próximos capítulos.

\section{APLICABILIDADE DO HOMICÍDIO CONTRA A MULHER POR RAZÕES DE GÊNERO ANTES DA LEI DO FEMINICÍDIO}

Antes da Lei n. 13.104/2015, não havia nenhuma punição em especial pelo fato de o homicídio ser praticado contra a mulher por razões da condição de sexo feminino. A depender do caso, o crime de feminicídio, poderia ser enquadrado como sendo homicídio qualificado por motivo torpe (art. 121, 2 , I) ou fútil (art. 121, §2, II). Não existia nenhuma previsão de uma pena maior para o fato de o crime ser cometido contra a mulher por razões de gênero, apenas, era aplicado juntamente com a pena a circunstância agravante, prevista no art. 61, II do $\mathrm{CP}$, que se refere a agravante da pena quando o agente comete o crime contra ascendente, descendente, irmão ou cônjuge.

Sua aplicabilidade era derivada por diversos motivos, sendo eles por ciúmes, raiva, ódio e em todas elas, ou de grande maioria o sujeito ativo era companheiro ou ex-companheiro da vítima mulher, que tomado desses sentimentos ceifava ou não a vida dela.

Servindo de exemplo para este estudo, o Tribunal de Justiça de Santa Catarina julgou um caso em que a vítima mulher 
foi quase levada a óbito pelo seu cônjuge. A vítima era constantemente ameaçada por ele, que não aceitava a separação do casal e a rejeição dela. Quando certa ocasião o acusado invadiu a residência da vítima e desferiu 4 (quatro) golpes de arma branca (faca) na sua ex-companheira, no qual, ele não atingiu seu objetivo por circunstâncias alheias a sua vontade. A sentença foi dada como procedente, com a dosimetria da pena de 10 anos e 1 mês.

[...] O motivo do crime foi torpe, consistente no inconformismo com o término do seu relacionamento, não aceitando a rejeição de sua ex-companheira. No entanto, tal circunstância qualifica o crime. [...] Passando à segunda fase da aplicação da pena, reconheço a agravante do art. 61, I, f, do Código Penal, pois o crime foi cometido com violência contra a mulher, na forma do art. $5^{\circ}$, III, da Lei n. 11.340/06, uma vez que o réu conviveu com a vítima por aproximadamente dez anos, conforme relatou em seu interrogatório judicial. [...] Para tanto, argumenta que "a razão de ser do motivo torpe se relaciona umbilicalmente com a situação familiar e afetiva existente entre agente e vítima; situação que tem como traço característico absolutamente comum o fato de que o agente tenta a morte de sua ex-companheira. (TJSC, Apelação Criminal n. 2015.002472-1, de São José, rel. Des. Rodrigo Collaço, Quarta Câmara Criminal, j. 12-03-2015).

Entende a jurisprudência de nossos tribunais que o marido ou amante que mata a companheira por vingança, ciúme ou ódio, age por motivo torpe ou fútil, o que qualifica a conduta à época dos fatos, ou seja, anteriores a lei vigente. Em se tratando de motivo torpe, transcreve-se os seguintes julgados:

Caracteriza motivo torpe, o fato de o marido, desprezado pela mulher que com ele não mais quer conviver, resolve vingar-se, desejando matá-la. O motivo é o antecedente psíquico da ação. No caso, a força que colocou em movimente o querer do agente ativo, que o levou ao gesto de matar a sua companheira, que somente não se consumou pelo fato 
de a vítima ter fingido que já se encontrava morta. (TJRJ, Apelação Criminal, rel. Paulo Sérgio Fabião, RT 733/659 apud, ELUF, p. 193, 2007)

É certo que a vingança, por si só, não torna torpe o motivo do delito, já que não é qualquer vingança que o qualifica. Entretanto, ocorre a qualificadora em questão se o acusado, sentindo-se desprezado pela amásia, resolve vingar-se, matando-a. (TJSP, Apelação Criminal, rel. Jarbas Mazzoni, RT 598/310 apud, ELUF, p. 193, 2007)

O motivo, é o antecedente psíquico da ação, a força que põe em movimento o querer e o transforma em ato: uma representação que impele à ação. No caso, a força que pôs em movimento o querer do agente ativo o antecedente psíquico que o levou ao ato de matar sua ex-companheira, foi a vingança, o ódio reprimido. Vingança contra quem não mais queria sujeitar-se a um companheiro incompreensivo, agressivo, mau, que a espancava sem motivo, que a deixava sem meios de subsistência. Justa e humana a vontade da ofendida de desejar e efetivar a separação. Lembra o jurista Baldassari Corurullo, referindo-se à torpeza do motivo, que "a baixeza do fim não está na natureza da necessidade, nem na do sentimento, está, precisamente, na antisocialidade que mostra o delinquente, em cujo ânimo o sentimento do altruísmo necessário à conservação da sociedade e, portanto, de si mesmo, não lograram vencer os impulsos próprios dos seres primitivos. (TJSP, Apelação Criminal. Rec., Rel. Weiss de Andrade, RJTJSP 73/312 apud ELUF, p.193, 2007)

Sendo réu e vítima casados, embora na ocasião do evento separados, não se pode cogitar ter sido torpe o móvel do crime, se a intenção do agente era, como o afirma, tentar reconciliação com a vítima, concitando-a a manter conjunção carnal. (TJSC, Apelação Criminal. Rel. AloysioGonçalves, RT 534/390 apud ELUF, p. 192, 2007.)

Nos dizeres da promotora de justiça Ana Lara Camargo de Castro:

O alcoolismo, drogadição e questões financeiras são fatores 
exacerbadores, mas é o machismo revelado no sentimento cotidiano de posse que determina a maioria absoluta de casos do tipo "Ela estava de saía curta, chegou em casa fora do horário combinado ou não havia feito a comida na hora certa". (NUCCI, 2014, grifo nosso)

Essas são principais afirmações dos agressores que veem as mulheres como objetos de sua propriedade, e ainda tentam culpá-las pelo ocorrido. Situações como estas podem ser caracterizadas como motivos fúteis por situações abrangentes de menosprezo ou discriminação à condição de mulher.

Sobre tal aspecto, merece ser trazido à baila alguns julgados que asseveram:

O fato de o réu ter ameaçado a vítima de morte porque ela se recusou a manter relação sexual com ele configura motivo fútil e justiça a aplicação da agravante no artigo 61, inciso II, alínea a, do Código Penal (violência contra a mulher em situação de vulnerabilidade). (TJ-DF, APR: 20140410039205, relator: Silvano Barbosa dos Santos, Data de Julgamento: 04/02/2016, $2^{\text {a }}$ Turma Criminal, DJ $15 / 02 / 2016$.)

HABEAS CORPUS. TENTATIVA DE HOMICIDIO. MOTIVO FÚTIL. VIOLÊNCIA DOMÉSTICA CONTRA A MULHER. ORDEM PÚBLICA. APLICAÇÃO DA LEI PENAL. CONDIÇÕES PESSOAIS FAVORÁVEIS. LIBERDADE PROVISÓRIA. NÃO CABIMENTO.

Paciente que, estimulado pela embriaguez golpeia com faca a sua companheira, na presença dos filhos da vítima, pelas simples circunstâncias de ser admoestado por estar vasculhando uma bolsa, manifestando estado de fúria em ambiente doméstico, em situação que não sugere fato isolado, revela comportamento que põe em risco a paz e a tranquilidade social, ou em outros termos, a ordem pública.(TJPE. Habeas Corpus: HC 4101126. Relator Fábio Eugênio Dantas de Oliveira Lima.DJ.22/02/2016.)

O paciente foi denunciado pela prática do crime de homicí- 
dio qualificado pelo motivo fútil, contra a mulher em razão do sexo feminino, em virtude de envolver violência doméstica, furto qualificado pelo abuso de confiança e ocultação de cadáver, tudo em concurso material (artigo 121, § $2^{\circ}$, II c.c. $\S 2^{\circ}$-A, I; artigo $155, \S 4^{\circ}$, II e $211, \mathrm{n} / \mathrm{f}$ do artigo 69, todos do Código Penal) [..] O crime foi cometido por motivo fútil, tendo em vista que se deu em razão de uma simples briga por motivo de ciúme entre a vítima e o denunciado. A vítima era companheira do denunciado, tendo os atos sido praticados contra a mulher por razões da condição de sexo feminino, uma vez que o ato delituoso se deu em situação típica de violência doméstica. No dia seguinte, 01 de julho de 2015, utilizando-se de uma faca de pão, o denunciado esquartejou o corpo de A.O. P e ocultou o cadáver colocando-o na caixa d'água da casa da vítima. (TJ-RJ. Habeas Corpus: HC 00651361720158190000 RJ 0065136-17.2015.8.19.0000. Relator Des.Denise Vaccari Pires. DJ 17/12/2015)

Dado o exposto que, os tribunais se pronunciaram várias vezes (anteriores à lei do feminicídio) no sentido de que o marido, ex-marido, namorado, amante ou ex-amante que mata a mulher em razão da condição de sexo feminino age por motivo torpe ou fútil, a mostrar os exemplos e julgados mencionados acima

Sabe-se que o feminicídio já poderia e, em alguns casos, já era classificado como crime hediondo (homicídio por motivo torpe, fútil etc.). Afinal, não há como negar torpeza e a futilidade na ação de matar uma mulher por discriminação de gênero (Exemplos: Matar uma mulher porque usa roupas consideradas inadequadas pelo agente ou porque não fez a comida corretamente ou não limpou a casa etc.). Mas esse entendimento não era uniforme. Daí a pertinência da nova Lei de n. 13.104/15, para dizer que todas essas situações configuram indiscutivelmente crime hediondo. Nos crimes anteriores a 10.03.2015 o motivo torpe continua sendo possível. O que não se pode é aplicar a lei nova (Lei n. 13.104/2015) para fatos anteriores a 
ela (lei nova maléfica não retroage). A virtude dessa inclusão de qualificadora, está incumbida no alerta que se faz da necessidade de se coibir com mais rigor a violência contra a mulher em razão da condição do sexo feminino.

\section{POSSIBILIDADE E CONVÍVIO DE DUAS QUALIFICADORAS SUBJETIVAS}

A nova circunstância qualificadora, trouxe a relevante controvérsia sobre a sua natureza, ou seja, se possui características de circunstância qualificadora objetiva ou subjetiva. Em face dessa acesa divergência, propõe-se o presente ensaio a enfrentar a questão da natureza subjetiva ou objetiva da nova circunstância qualificadora inserida no Código Penal introduzia por meio da Lei $\mathrm{n}^{\mathrm{o}} 13.104 / 2015$, com o objetivo de contribuir para o avanço da pesquisa ao aludido tema.

Nem todo o homicídio de uma mulher é necessariamente um feminicídio, é necessário analisar os elementos que identificam que o homicídio realmente é um feminicídio. Para ser caracterizado feminicídio a morte precisa ser causada por razões da condição do sexo feminino.

Segundo o delegado José Melo "Nem todo o assassinato de mulher por homem é feminicídio" (TOMAZ, 2017), por exemplo, se há morte de uma mulher, ainda que por homem, em uma briga originada de um desentendimento no trânsito, temos um crime de homicídio qualificado por motivo fútil (art. 121, §2, II, do CP) e não o feminicídio. Ou seja, não será todo o homicídio de mulher configurado como feminicídio, mas sim aqueles que revelem as circunstâncias de "razões de condição de sexo feminino".

De tal forma, uma mulher morta em um roubo (art. 157 do $\mathrm{CP}$ ), não é vítima de feminicídio, por faltar-lhe as duas características exigidas por lei: a violência doméstica e familiar (art. 
$121, \S 2^{\circ}$-A, I) e o menosprezo ou discriminação da condição de mulher (art. 121, $\S 2^{\circ}$-A, II). Para tanto, nas palavras de Gomes, para que haja o feminicídio a morte tem que ser, necessariamente "[..] violenta, não acidental e não ocasional de uma mulher em decorrência justamente da sua condição de gênero" (GOMES, 2015, p. 193), assim, para que ocorra feminicídio, é necessário que ao fato esteja associada às razões da condição de sexo feminino, que efetivamente ocorrerá quando envolver violência doméstica e familiar ou menosprezo e discriminação.

\section{NATUREZA QUALIFICADORA DO FEMINICÍDIO}

Desde a entrada da Lei, surgiu o seguinte questionamento: a qualificadora do feminicídio é de natureza objetiva ou subjetiva?

A partir de então, a doutrina e a jurisprudência passaram a debater acerca da natureza do crime de feminicídio. A discussão traz apreço à questão que envolve a natureza objetiva ou subjetiva da qualificadora. Há uma divergência entre vários doutos na seara jurídica, há os que defendem o feminicídio ser de natureza objetiva e há os que defendem ser de natureza subjetiva, por isso faz-se necessário explanar sobre ambos os lados. Com o propósito de aclarar este debate, apresenta-se a definição das naturezas jurídicas supracitadas e o posicionamento de alguns doutrinadores sobre cada questão.

As qualificadoras objetivas dizem respeito ao meio e modo de execução do crime, que se relacionam ao fato praticado e se comunicam no concurso de pessoas, desde que ingressem na esfera de conhecimento do agente. Para a incidência do feminicídio como circunstância qualificadora do crime de homicídio, não se questiona o motivo do crime ou o animus do agente, mas se deve analisar se o fato se amolda ao contexto de violência doméstica. 
Contudo, são qualificadoras as descritas no art. 121, §2 , incisos III e IV, do CP, in verbis:

III: com emprego de veneno, fogo, explosivo, asfixia, tortura ou outro meio insidioso ou cruel, ou de que possa resultar perigo comum;

IV: à traição, de emboscada, ou mediante dissimulação ou outro recurso que dificulte ou torne impossível a defesa do ofendido; (BRASIL, 1940.)

Entendendo ser o feminicídio uma qualificadora de natureza objetiva, o promotor de justiça, Amom Albernaz Pires ressalta:

[...] se, de um lado, a verificação da presença ou ausência das qualificadoras subjetivas do motivo fútil ou torpe (ou ainda da qualificadora do inciso V) demandará dos jurados avaliação valorativa acerca dos motivos inerentes ao contexto fático-probatório que levaram o autor a agir como agiu, por outro lado, a nova qualificadora do feminicídio tem natureza objetiva, pois descreve um tipo de violência específico contra a mulher (em razão da condição de sexo feminino) e demandará dos jurados mera avaliação objetiva da presença de uma das hipóteses legais de violência doméstica e familiar (art. $121, \S 2^{\circ} \mathrm{A}, \mathrm{I}$, do CP, c/c art. $5^{\circ}$, I, II e III, da Lei 11.340/06) ou ainda a presença de menosprezo ou discriminação à condição de mulher (art. 121, § $2^{\circ}$-A, II, do CP).

[...] é objetiva a análise da presença do modelo de violência baseada no gênero (ou em razão da condição do sexo feminino), positivada na Lei Maria da Penha e na Convenção de Belém do Pará e agora incorporada pela Lei no 13.104/2015 com a expressão "violência doméstica e familiar", já que a Lei Maria da Penha já reputa como hipóteses desse tipo de violência àquelas transcritas acima (art. $5^{\circ}$, incisos I, II e III). (PIRES, 2015).

Nesse mesmo sentido, Vicente de Paula Rodrigues Maggio, esclarece-nos da seguinte forma:

Com o advento da Lei 13.104/2015, que incluiu mais uma 
qualificadora ao crime de homicídio, cinco passam a ser as espécies de qualificadoras: 1) pelos motivos (incisos I a II paga, promessa ou outro motivo torpe, e pelo motivo fútil); 2) meio empregado (inciso III - veneno, fogo, explosivo, asfixia, etc.); 3) modo de execução (inciso IV - traição, emboscada, dissimulação, etc.), 4) por conexão (inciso V - para assegurar a execução, a ocultação, a impunidade ou vantagem de outro crime) e, a novidade, 5) pelo sexo da vítima (inciso VI - contra mulher por razões da condição de sexo feminino). Para este autor as qualificadoras previstas nos incisos III, IV e VI são objetivas. (MAGGIO, 2015, p. 96)

Entendendo ser qualificadora objetiva, o TJDF concluiu que, em caso de homicídio em situação de violência doméstica, o feminicídio é qualificadora objetiva, vejamos:

PENAL. RECURSO EM SENTIDO ESTRITO. RÉU PRONUNCIADO POR HOMICÍDIO COM MOTIVO TORPE. MORTE DE MULHER PELO MARIDO EM CONTEXTO DE VIOLÊNCIA DOMÉSTICA E FAMILIAR. PRETENSÃO ACUSATÓRIA DE INCLUSÃO DA QUALIFICADORA DO FEMINICÍDIO. PROCEDÊNCIA. SENTENÇA REFORMADA. 1. Réu pronunciado por infringir o artigo $121, \S 2^{\circ}$, inciso I, do Código Penal, depois de matar a companheira a facadas motivado pelo sentimento egoístico de posse. 2. Os protagonistas da tragédia familiar conviveram sob o mesmo teto, em união estável, mas o varão nutria sentimento egoístico de posse e, impelido por essa torpe motivação, não queria que ela trabalhasse num local frequentado por homens. A inclusão da qualificadora agora prevista no artigo $121, \S 2^{\circ}$, inciso VI, do Código Penal, não poderá servir apenas como substitutivo das qualificadoras de motivo torpe ou fútil, que são de natureza subjetiva, sob pena de menosprezar o esforço do legislador. A Lei 13.104/2015 veio a lume na esteira da doutrina inspiradora da Lei Maria da Penha, buscando conferir maior proteção à mulher brasileira, vítima de condições culturais atávicas que lhe impuseram a subserviência ao homem. Resgatar a dignidade perdida ao longo da história da dominação masculina foi a ratioessendi da nova lei, e o seu sentido teleológico estaria perdido se fosse sim- 
plesmente substituída a torpeza pelo feminicídio. Ambas as qualificadoras podem coexistir perfeitamente, porque é diversa a natureza de cada uma: a torpeza continua ligada umbilicalmente à motivação da ação homicida, e o feminicídio ocorrerá toda vez que, objetivamente, haja uma agressão à mulher proveniente de convivência doméstica familiar. Recurso provido. (TJDF - Recurso em Sentido Estrito. RSE: 20150310069727, Relator: George Lopes Leite, Data de Julgamento: 29/10/2015, 1a Turma Criminal, Publicado no DJe : 11/11/2015.)

Ainda:

[..] O feminicídio é uma qualificadora de natureza objetiva, enquanto o motivo torpe é de natureza subjetiva. Trata-se de duas qualificadoras distintas e autônomas, sendo perfeitamente possível a coexistência de ambas, não havendo, portanto, que se falar em bis in idem. (TJMG Recurso em Sentido Estrito. RSE: 10024151883493001, Relator: Paulo Calmon Nogueira da Gama. Data de Julgamento: 07/04/2016, 7a Câmara Criminal, Publicado no DJe: $15 / 04 / 2016$.

No entendimento do Tribunal de Justiça do Distrito Federal, declara que é possível conciliar o crime de homicídio com outra qualificadora subjetiva, pois é diversa a natureza de cada uma, afirmando este julgado que a natureza qualificadora do feminicídio é objetiva.

Já as qualificadoras de natureza subjetiva situam-se na esfera interna do agente, são aquelas relacionadas com a motivação do crime. Quem pratica crime contra a mulher por razões da condição de sexo feminino pratica homicídio na sua forma qualificada por um motivo, a razão da conduta é que qualifica o crime, assim, temos uma natureza subjetiva.

Nesse sentido, expõem-se os argumentos de Rogério Sanches Cunha e Alice Bianchini, que afirmam ser a qualificadora do feminicídio subjetiva em qualquer circunstância: 
É impossível pensar num feminicídio, que é algo abominável, reprovável, repugnante à dignidade da mulher, que tenha sido praticado por motivo de relevante valor moral ou social ou logo após injusta provocação da vítima. Uma mulher usa minissaia. Por esse motivo fático o seu marido ou namorado lhe mata. E mata por uma motivação aberrante de achar que a mulher é de sua posse, que a mulher é objeto, que a mulher não pode contrariar as vontades do homem. Nessa motivação há uma ofensa à condição de sexo feminino. O sujeito mata em razão da condição do sexo feminino. Em razão disso, ou seja, por causa disso. Seria uma qualificadora objetiva se dissesse respeito ao modo ou meio de execução do crime. A violência de gênero não é uma forma de execução do crime, sim, sua razão, seu motivo. (CUNHA; BIANCHINI, 2015)

Para Luiz Flávio Gomes e Alice Bianchini “a qualificadora do feminicídio é nitidamente subjetiva, segundo eles, no feminicídio o agente mata em razão da condição do sexo feminino". (GOMES; BIANCHINI, 2015). Diante, seria uma qualificadora objetiva no que diz respeito ao modo ou meio de execução do crime, não sendo a violência de gênero uma forma de execução do delito, mas sua razão, seu motivo, por isso de natureza subjetiva.

Tratando-se de uma qualificadora subjetiva Rogério Sanches Cunha e Ronaldo Batista Pinto trazem à tona:

[..] a qualificadora do feminicídio é subjetiva, pressupondo motivação especial: o homicídio deve ser cometido contra a mulher por razões da condição de sexo feminino. Mesmo no caso do inc. I do $\S 2^{\circ}$-A, o fato de a conceituação de violência doméstica e familiar ter um dato objetivo, extraído da lei, não afasta a subjetividade. Isso porque o $\S 2^{\circ}$-A é apenas explicativo; a qualificadora está verdadeiramente no inc. VI do $\S 2^{\circ}$, que, ao estabelecer que o homicídio se qualifica quando cometido por razões da condição do sexo feminino, deixa evidente que isso ocorre pela motivação, não pelos meios de execução. (CUNHA; PINTO, 2015, p. 84) 
O promotor de justiça, Francisco Dirceu Barros, no que diz respeito aos elementos caracterizantes do Art. 121, IV do CP, argumenta que tais não são formas de execução, "[..] a violência doméstica, familiar e também o menosprezo ou discriminação à condição de mulher, não são formas de execução do crime, e sim, sua motivação delitiva; portanto, o feminicídio é uma qualificadora subjetiva." (BARROS, 2015)

Não há como negar que a violência doméstica ou familiar e o menosprezo e discriminação foram definidos como crimes praticados "contra a mulher por razões da condição do sexo feminino" e que tratam de elementos motivantes para a prática do crime. Em resumo, é evidente que o feminicídio possui natureza subjetiva, por exigir que a razão (motivo) do crime seja a condição feminina da vítima.

\section{CONCURSO ENTRE O FEMINICÍDIO E DEMAIS QUALIFICADORAS SUBJETIVAS}

Sabendo que nem todas as qualificadoras são compatíveis entre si. Alguns doutrinadores defendem que nunca poderão em um mesmo homicídio coexistir duas qualificadoras de natureza subjetiva. Já no que se refere às qualificadoras de natureza objetiva é pacífico o entendimento de que elas podem coexistir e são compatíveis com uma circunstância subjetiva, relacionada ao motivo ou finalidade.

Ainda se questiona em qual das qualificadoras o feminicídio é compatível? Em alguns casos, doutrinadores entendem que o feminicídio possui natureza subjetiva sendo somente compatível com qualificadoras de meio e modo, ou seja, de natureza objetivas.

Mas em recentes julgados, pode-se perceber que é possível a compatibilidade do feminicídio em face da presença de outra qualificadora subjetiva no crime de homicídio. Vejamos: 
RECURSO EM SENTIDO ESTRITO. TRIBUNAL DO JÚRI. PRONÚNCIA. HOMICÍDIO QUALIFICADO PELO MOTIVO TORPE, PELO EMPREGO DE MEIO QUE DIFICULTOU A DEFESA DA VÍTIMA E EM RAZÃO DE SER PRATICADO CONTRA MULHER (FEMINICÍDIO) (ART. 121, § $2^{\circ}$, INCISOS I, IV, VI E $\S$ $2^{\circ}$-A, INCISO I, DO CÓDIGO PENAL) E HOMICÍDIO QUALIFICADO POR MOTIVO FÚTIL E PELO EMPREGO DE MEIO QUE DIFICULTOU A DEFESA DA VÍTIMA (ART. $121, \S 2^{\circ}$, INCISOS II E IV, DO CÓDIGO PENAL). RECURSO DA DEFESA. PRELIMINAR. PRETENDIDA A DECLARAÇÃO DA NULIDADE DA DECISÃO DE PRONÚNCIA DIANTE DA AUSÊNCIA DE FUNDAMENTAÇÃO QUANTO ÀS QUALIFICADORAS. INSUBSISTÊNCIA. DECISÃO QUE FOI MOTIVADA, NA FORMA DO ARTIGO 413, § $1^{\circ}$, DO CÓDIGO DE PROCESSO PENAL. PREFACIAL AFASTADA. MÉRITO. PLEITO DE EXCLUSÃO DAS QUALIFICADORAS. INDÍCIOS QUE DÃO MARGEM À INCIDÊNCIA DAS QUALIFICADORAS DESCRITAS NA EXORDIAL. RECONHECIMENTO DA QUALIFICADORA DO FEMINICÍDIO QUE NÃO DENOTA INCOMPATIBILIDADE COM A QUALIFICADORA DO MOTIVO TORPE, PORQUANTO UTILIZADO FUNDAMENTO DIVERSO. EVENTUAIS DÚVIDAS QUE DEVERÃO SER DIRIMIDAS PELA CORTE POPULAR. INCIDÊNCIA DO PRINCÍPIO IN DUBIO PRO SOCIETATE. MANUTENÇÃO DA PRONÚNCIA QUE SE IMPÕE. DECISÃO IRRETOCADA. RECURSO CONHECIDO E DESPROVIDO.(TJSC. Recurso em Sentido Estrito. RSE: 0013419-23.2015.8.24.0033, Relator: Des. Paulo Roberto Sartorato. Primeira Câmara de Direito Criminal. Data do julgamento: 05/10/2017.)

Observando que o Magistrado de primeiro grau indicou de maneira comedida, porém, concretamente, os fundamentos que fizeram com que reconhecesse a possibilidade de configuração das qualificadoras mencionadas na denúncia, não há falar em nulidade da decisão de pronúncia por ausência de fun- 
damentação.

$\mathrm{Na}$ fase da pronúncia, Júlio Fabbrini Mirabete afirma que somente as qualificadoras "podem ser excluídas quando manifestamente improcedentes, sem qualquer apoio nos autos, vigorando também quanto a elas o princípio in dubio pro societate". (MIRABETE, 2001, p.921)

Nos autos do Recurso em Sentido Estrito, retirara-se do trecho extraído do parecer da Procuradoria-Geral de Justiça na fl. 663:

[...] inexiste óbice na admissão simultânea do motivo torpe, decorrente do suposto cometimento dos fatos por ciúme e por não aceitar que a vítima trabalhasse como vigilante em uma casa noturna, e do feminicídio, porquanto, embora possuam relação, não se fundamentam nas mesmas razões. A motivação do ilícito, de caráter subjetivo, é relacionada à causa da ação do agente (qualificada por motivo torpe), enquanto a vulnerabilidade da vítima (feminicídio) sopesa as circunstâncias desta na relação íntima de afeto.(TJSC. Recurso em Sentido Estrito. RSE: 0013419-23.2015.8.24.0033, Relator: Des. Paulo Roberto Sartorato. Primeira Câmara de Direito Criminal. Data do julgamento: 05/10/2017.)

Em poucas palavras, o denunciado inconformado com o término do relacionamento que mantinha com a vítima (excompanheira) dirige-se até a frente da residência da vítima, e efetua disparos de arma de fogo. Afirma-se que, o crime foi praticado contra a mulher por razões da condição do sexo feminino da vítima, visto que praticado no contexto da violência doméstica e familiar; bem como por motivo torpe, porque o denunciado agiu motivado pelo sentimento de vingança, inconformado pelo término e pelo fato de a vítima trabalhar como vigilante de uma casa noturna.

Explicando de forma sucinta o caso discutido nos autos do Recurso de Sentido Estrito (n. 0013419-23.2015.8.24.0033) 
fora julgado no Tribunal de Justiça de Santa Catarina, de relatoria do Des. Paulo Roberto Sartorato, da Primeira Câmara de Direito Criminal, em que decidiu por votação unânime, conhecer do recurso, rejeitar a preliminar e, no mérito, negar-lhe provimento. Alegando ainda, que não é possível afastar as qualificadoras em relação à vítima, visto que a incidência de tais circunstâncias também deverá ser objeto da deliberação do Corpo de Jurados.

Nessa mesma seita, o Tribunal de Justiça de Santa Catarina entende a seguinte posição:

RECURSO EM SENTIDO ESTRITO. CRIME DOLOSO CONTRA A VIDA. HOMICÍDIO QUALIFICADO TENTADO. CÓDIGO PENAL, ART. 121, § 2. ${ }^{\circ}$, II, IV E VI, C/C ART. 14, II. PRONÚNCIA. RECURSO DEFENSIVO.QUALIFICADORAS. EXCLUSÃO. INVIABILIDADE. MOTIVO FÚTIL. CIÚMES. DIFICULTAÇÃO DA DEFESA DA VÍTIMA. PRESENÇA DE CIRCUNSTÂNCIAS QUE INDICAM A POSSIBILIDADE DE DIMINUIÇÃO DA DEFESA. FEMINICÍDIO. VIOLÊNCIA PRATICADA CONTRA A COMPANHEIRA. CRIME EM RAZÃO DA CONDIÇÃO DE SEXO FEMININO. ÂMBITO DOMÉSTICO E FAMILIAR. EXISTÊNCIA DE RESPALDO PROBATÓRIO. ADMISSÃO DAS QUALIFICADORAS. REMESSA DA ANÁLISE AO TRIBUNAL DO JÚRI.(TJSC. Recurso em Sentido Estrito. RSE: 0007594-62.2015.8.24.0045, Relator: Des. Roberto Lucas Pacheco, Quarta Câmara Criminal, Data do julgamento: 09/03/2017.)

Havendo razoável apoio nos autos, cabe ao Tribunal do Júri decidir se o crime foi praticado por ciúme e se, no caso concreto, esse sentimento configura a qualificadora do motivo fútil.

Existem elementos nos autos que permitem concluir, ao menos nesta fase processual, que o crime foi, em tese, praticado mediante recurso que impossibilitou a defesa da vítima. Portanto, havendo a possibilidade de reconhecimento hipotético da qualificadora, inviável seu afasta- 
mento em sede de recurso em sentido estrito, competindo ao Conselho de Sentença dirimir a questão quando do julgamento em plenário.(TJSC, Recurso Criminal n. 2013.078679-1, da Capital, rel. Des. Jorge Schaefer Martins, Quarta Câmara Criminal, j. em 27.2.2014, grifo nosso)

É admissível a qualificadora do feminicídio quando houver elementos a indicar ter sido o fato praticado em situação de violência doméstica e familiar, prevista na Lei n. 11.340/06 (CP, art. 121, § 2. . -A, I).

ADMISSÃO DAS QUALIFICADORAS DO MOTIVO
FÚTIL (CIÚMES) E DO FEMINICÍDIO. ALEGAÇÃO
DE DUPLA VALORAÇÃO DA MESMA CIRCUNSTÂN-
CIA PARA A CARACTERIZAÇÃO DAS QUALIFICA-
DORAS. NÃO OCORRÊNCIA. MOTIVAÇÃO DO DELI-
TO QUE É ESSENCIALMENTE LIGADA AO AGENTE.
FEMINICÍDIO QUE LEVA EM CONTA A CONDIÇÃO
VULNERÁVEL DA VÍTIMA. REMESSA DE ANÁLISE
DOS FATOS AOS JURADOS.(TJSC. Recurso em Sentido
Estrito. RSE: 0007594-62.2015.8.24.0045, Relator: Des.
Roberto Lucas Pacheco, Quarta Câmara Criminal, Data do
julgamento: 09/03/2017)

Inexiste óbice à admissão da qualificadora do motivo fútil, decorrente do suposto cometimento dos fatos por ciúme, e do feminicídio, porquanto, embora possuam relação, não se fundamentam nas mesmas razões. A motivação, de caráter subjetivo, é relacionada à causa da ação do agente, enquanto a vulnerabilidade da vítima (feminicídio) sopesa as circunstâncias desta na relação íntima de afeto.

No exemplo acima, o denunciado inconformado com o término do relacionamento que mantinha com a vítima, dirige-se até o seu local de trabalho e desfere-lhe 14 (catorze) golpes de faca. Resta constatado que o crime foi cometido por motivo fútil, por razões ligadas aos ciúmes e pelo feminicídio quando o crime envolve violência doméstica e familiar, já que a vítima 
figura na condição de ex-companheira do denunciado. A Colenda Quarta Câmara Criminal é unânime em negar provimento do recurso apresentado pelo denunciado.

Há ainda certas doutrinas que questionam a ocorrência do bis in idem entre as qualificadoras do motivo fútil e do feminicídio, por estarem embasadas pela mesma razão, o que não merece ser acolhido pois, a exclusão das qualificadoras só é possível em situações excepcionais, quando ficar comprovado serem manifestamente improcedentes.

É o posicionamento do Supremo Tribunal Federal de que "A jurisprudência desta Corte está assentada no sentido de que apenas a qualificadora manifestamente improcedente deve ser excluída da pronúncia”. (STF - Habeas Corpus. HC: 106902, Relator: Min. RICARDO LEWANDOWSKI, Primeira Turma, Data de Julgamento: 29/03/2011, Dje: 03/05/2011)

Nesse sentido, colhe-se julgado pela mesma Câmara:

AFASTAMENTO DA QUALIFICADORA. INVIABILIDADE. DELITO SUPOSTAMENTE PRATICADO POR CIÚMES. CONJUNTO PROBATÓRIO QUE INDICA SER POSSÍVEL A SUA CONFIGURAÇÃO. ANÁLISE VALORATIVA DA PROVA QUE COMPETE AO CONSELHO DE SENTENÇA. PRECEDENTES JURISPRUDENCIAIS.

(TJSC - Recurso em Sentido Estrito. RSE: 2012.0393218, Des. Subst. José Everaldo Silva, Data de Julgamento: 29/11/2012, 4a Câmara Criminal.)

Sob relatoria da Ministra Laurita Vaz, defende que "Só podem ser excluídas da sentença de pronúncia as circunstâncias qualificadoras manifestamente improcedentes, uma vez que não se pode usurpar do Tribunal do Júri o pleno exame dos fatos da causa" (STJ, Habeas Corpus n. 162401/GO, rela. Mina. Laurita Vaz, j. em 27/3/2012) 
Na mesma linha de raciocínio, o STJ é firme ao afirmar que:

Não se pode afastar uma qualificadora por mera opção hermenêutica do juiz, de modo que o julgador somente pode retirar da pronúncia a qualificadora que, objetivamente inexista, mas não a que, subjetivamente julgar não existir. (STJ - Recurso Especial. REsp 1430435/RS, Rel. Ministro Rogério Schietti Cruz, Sexta turma, Data de julgamento:17/03/2015, DJe 30/03/2015).

Em outras palavras, não se pode subtrair da apreciação do Conselho de Sentença uma circunstância que, numa análise objetiva, mostra-se procedente, como nos casos acima mencionados.

O Doutrinador Guilherme de Souza Nucci, esclarece que presentes as qualificadoras e causas de aumento as mesmas devem ser mantidas na pronúncia para apreciação do Tribunal do Júri, vejamos:

As circunstâncias legais, vinculadas ao tipo penal incriminador, denominadas qualificadoras e causas de aumento são componentes da tipicidade derivada. Logo, constituem a materialidade do delito, envolvendo o fato básico e todas as suas circunstâncias. Quando presentes, devem ser mantidas na pronúncia para a devida apreciação pelo Tribunal do Júri. Entretanto, se as provas não as sustentarem, devem ser afastadas pelo magistrado. Na dúvida, o juiz mantém as referidas circunstâncias legais para a apreciação dos jurados; possuindo certeza de que não há amparo algum para ampará-las, torna-se fundamental o seu afastamento. (NUCCI, 2013, p. 807)

Contudo, verifica-se nos julgados acima a possibilidade de duas qualificadoras subjetivas concorrerem com a qualificadora de feminicídio. Sendo assim percebe-se que há opiniões divergentes entre os doutrinadores, porém predomina a corrente de que a qualificadora do feminicídio é subjetiva. Isso porque tal crime ocorre exclusivamente pela motivação 
do delito, que são consideradas subjetivas, pois não caberia falar em natureza objetiva por não dizer respeito ao modo ou meio de execução do crime.

\section{CONCLUSÃO}

Para fatos anteriores a Lei n. 13.104/2015, não havia nenhuma punição em especial pelo fato de o homicídio ser praticado contra a mulher por razões da condição de sexo feminino. A depender do caso, crimes deste tipo eram enquadrados como sendo de natureza qualificada por motivo torpe (art. 121, §2, I) ou fútil (art. 121, §2, II). Não existindo nenhuma previsão de uma pena maior ou agravante para o fato de o crime ser cometido contra a mulher por razões de seu gênero.

Assim, com o intuito de ampliar a proteção da mulher vitimada pela violência de gênero e assegurando-lhes maior proteção, verificou-se que a Lei do Feminicídio de n. 13.104/2015, veio a ser um novo mecanismo de combate à violência doméstica e em especial dos homicídios qualificados pelo feminicídio, uma vez que precisava-se tomar uma atitude para diminuir a quantidade estarrecedora de morte de mulheres em decorrência da discriminação de gênero ou violência doméstica em nosso país, haja vista que este tipo de homicídio qualificado ocorre diariamente dentro das residências, muitas vezes presenciados por ascendentes ou descendentes, com utilização de meios de execução bastante cruéis que ocasionam sofrimento a vítima.

Das análises preponderantes realizadas no decorrer deste artigo, a doutrina posiciona-se que a natureza da qualificadora de feminicídio é de ordem subjetiva. Há certas divergências quanto à sua natureza. Assim, como sustentado por alguns doutrinadores e tribunais, em especial, o Supremo Tribunal Federal e o Superior Tribunal de Justiça, já definiram indicativos no sentido de tratar a violência contra a mulher 
como violência estrutural e institucionalizada, ou seja, defende-se que a violência de gênero não é uma forma de execução do crime, mas sim sua razão ou seu motivo, pois não caberia falar em natureza objetiva por não dizer respeito ao modo ou meio de execução do crime.

Não há outro caminho senão enveredar pelo entendimento de que o feminicídio é uma qualificadora de índole subjetiva, consequentemente pode concorrer com as qualificadoras de natureza subjetiva. Isso significa que as qualificadoras consideradas como motivo torpe ou fútil, poderão ser cumuladas ao feminicídio, permitindo punições mais rigorosas para crimes cometidos nessas circunstâncias. Pleiteia o STJ que não se pode afastar uma qualificadora por mera opção hermenêutica do juiz, de modo que o julgador somente pode retirar da pronúncia a qualificadora que, objetivamente inexista, mas não a que, subjetivamente julgar não existir, portanto, sendo admissível a consonância entre as mesmas qualificadoras subjetivas.

Diante da análise do problema proposto para este estudo, conclui-se que, a hipótese inicial levantada é verdadeira na medida que deve se reconhecer o esforço legislativo em castigar rigorosamente o feminicídio, com total intuito em punir e erradicar a violência de gênero contra a mulher.

\section{REFERÊNCIAS}

BARROS, Francisco Dirceu. "Estudo completo do feminicídio". 2015. Disponível em: http://www.impetus.com.br/artigo/876/estudo-completo-do-feminicidio. Acesso em: 28 abr. 2019.

BRASIL. Código penal (1940). Disponível em: http://www.planalto.gov.br/ccivil_03/ Decreto-Lei/Del2848compilado.htm. Acesso em: 19 abr. 2019.

BRASIL. Lei $\mathbf{n}^{\mathbf{0}}$ 13.104, de 9 de março de 2015. Altera o art. 121 do Decreto-Lei $\mathrm{n}^{\mathrm{o}}$ 2.848, de 7 de dezembro de 1940 - Código Penal. Disponível em: http:/www.planalto. gov.br/ccivil_03/_ato2015-2018/2015/lei/113104.htm. Acesso em: 20 maio 2019.

BRASIL. Supremo Tribunal Federal. Habeas Corpus n. 106902. $1^{\text {a }}$ Turma. Brasília DF. Relator: Min. Ricardo lewandowski. Data de Julgamento: 29/03/2011. Disponível em: http://redir.stf.jus.br/paginadorpub/paginador.jsp?docTP=TP\&docID=1137242. 
Acesso em: 20 maio 2019.

BRASIL. Superior Tribunal de Justiça. Habeas Corpus n. 162401/GO. $5^{\text {a }}$ Turma. Relator: Mina. Laurita Vaz. Data de Julgamento em 27/3/2012. Disponível em: https://ww2.stj.jus.br/processo/revista/documento/mediado/?componente=ITA\&sequencial $=1134495 \&$ num_registro $=201000265568 \&$ data $=20120403 \&$ formato $=$ PDF. Acesso em: 20 maio 2019.

BRASIL. Superior Tribunal de Justiça. Recurso Especial 1430435/RS. 6 a Turma. Relator: Ministro Rogério Schietti Cruz. Data de julgamento:17/03/2015. Disponível em: https://ww2.stj.jus.br/processo/revista/documento/mediado/?componente=ITA\&sequencial $=1391727 \&$ num_registro $=201400149818 \&$ data $=20150330 \&$ formato $=$ PDF. Acesso em: 20 maio 2019.

BRASIL. Tribunal de Justiça do Distrito Federal. Apelação Criminal n. 20140410039205, $2^{\text {a }}$ Turma Criminal. Brasília, DF. Relator: Silvano Barbosa dos Santos. Data de Julgamento: 04/02/2016. Disponível em:https://pesquisajuris.tjdft. jus.br/IndexadorAcordaos-web/sistj?visaoId=tjdf.sistj.acordaoeletronico.buscaindexada.apresentacao.VisaoBuscaAcordao\&nomeDaPagina=buscaLivre2\&buscaPorQuery $=1 \&$ baseSelecionada=BASE_ACORDAO_TODAS\&filtroAcordaosPublicos $=$ false \&camposSelecionados $=[$ ESPELHO $] \&$ argumentoDePesquisa $=\&$ numero $=20140410039205 \&$ tipoDeRelator $=$ TODOS\&dataFim $=\&$ indexacao $=\&$ ramoJuridico $=\&$ baseDados $=[$ TURMAS_RECURSAIS, \%20BASE_ACORDAOS_IDR, $\% 20$ BASE_ACORDAOS]\&tipoDeNumero=Processo\&tipoDe $\bar{D}$ ata=DataPublicacao\&ementa $=$ \&filtroSegredoDeJustica $=$ false $\&$ desembargador $=83 \&$ dataInicio $=\&$ legisla$\mathrm{cao}=\&$ orgaoJulgador $=\&$ numeroDaPaginaAtual $=1 \&$ quantidadeDeRegistros $=20 \&$ tota1Hits=1. Acesso em: 20 maio 2019.

BRASIL. Tribunal de Justiça de Minas Gerais - Recurso em Sentido Estrito n. 10024151883493001. $7^{\text {a }}$ Câmara Criminal. Minas Gerais - MG. Relator: Paulo Calmon Nogueira da Gama. Data de Julgamento: 07/04/2016. Disponível em: https:// www5.tjmg.jus.br/jurisprudencia/pesquisaNumeroCNJEspelhoAcordao.do;jsessioni$\mathrm{d}=$ 5C282E1692194A37E7DD8FE8C27CE48A.juri_node2?numeroRegistro=1\&totalLinhas $=1 \&$ linhasPorPagina $=10 \&$ numeroUnico $=1.0024 .15 .1883493 \% 2$ F001\&pesquisaNumeroCNJ=Pesquisar. Acesso em: 20 maio 2019.

BRASIL. Tribunal de Justiça do Distrito Federal. Recurso em Sentido Estrito n. 20150310069727. $1^{\text {a }}$ Turma Criminal. Brasília - DF. Relator: George Lopes Leite. Data de Julgamento: 29/10/2015. Disponível: https://tj-df.jusbrasil.com.br/jurisprudencia/254720142/recurso-em-sentido-estrito-rse-20150310069727. Acesso em: 20 maio 2019.

BRASIL. Tribunal de Justiça do Pernambuco. Habeas Corpus n. 4101126. $1^{\text {a }}$ Câmara Regional de Caruaru - $1^{\text {a }}$ Turma. Pernambuco - PE. Relator Fábio Eugênio Dantas de Oliveira Lima. Data de Julgamento: 22/02/2016. Disponível em: http://www.tjpe. jus.br/consultajurisprudenciaweb/downloadInteiroTeor?codProc=532804\&tipoJuris=1141\&orig=FISICO. Acesso em: 20 maio 2019.

BRASIL. Tribunal de Justiça do Rio de Janeiro. Habeas Corpus n. 00651361720158190000. $5^{\text {a }}$ Câmara Criminal. Rio de Janeiro - RJ. Relatora Des. Denise Vaccari Pires. Data de Julgamento: 17/12/2015. Disponível em: http://www1.tjrj. jus.br/gedcacheweb/default.aspx?UZIP=1\&GEDID=0004D2B8F679ABEDC476BE2696B8BA291DB8C50440391650\&USER=. Acesso em: 20 maio 2019. 
BRASIL, Tribunal de Justiça de Santa Catarina. Apelação Criminal n. 2015.0024721, Quarta Câmara Criminal, São José, SC. Relator: Des. Rodrigo Collaço, Data de Julgamento: 12-03-2015. Disponível em: http://busca.tjsc.jus.br/jurisprudencia/html. do?q=\&only_ementa=\&frase=\&id=AAAbmQAACAALL15AAB\&categoria=acordao. Acesso em: 20 maio 2019.

BRASIL. Tribunal de Justiça de Santa Catarina. Recurso em Sentido Estrito n. 0007594-62.2015.8.24.0045. $4^{\text {a }}$ Câmara Criminal. Palhoça - SC. Relator: Des. Roberto Lucas Pacheco. Data do julgamento: 09/03/2017. Disponível em: http://busca.tjsc.jus. br/jurisprudencia/html.do?q=\&only_ementa $=\&$ frase= \&id=AABAg7AADAAOlGnAAH\&categoria=acordao_5. Acesso em: 20 maio 2019.

BRASIL. Tribunal de Justiça de Santa Catarina. Recurso em Sentido Estrito n. 0013419-23.2015.8.24.0033. $1^{\text {a }}$ Câmara Criminal. Itajaí - SC. Relator: Paulo Roberto Sartorato. Data de julgamento: 05/10/2017. Disponível em: http://busca.tjsc.jus.br/jurisprudencia/html.do?q=\&only_ementa $=\&$ frase= $=$ id $=$ AABAg7AAEAAEpjjAAG\&categoria=acordao_5. Acesso em: 20 maio 2019.

BRASIL. Tribunal de Justiça de Santa Catarina. Recurso em Sentido Estrito n. 2012.039321-8. $4^{a}$ Câmara Criminal. Brusque - SC. Relator Des. Subst. José Everaldo Silva. Data de Julgamento: 29/11/2012. Disponível em: http://busca.tjsc.jus.br/jurisprudencia/html.do?q=\&only_ementa=\&frase=\&id=AAAbmQAACAAAWMwAAQ\&categoria=acordao. Acesso em: 20 maio 2019.

BRASIL. Tribunal de Justiça de Santa Catarina. Recurso em Sentido Estrito n. 2013.078679-1. $4^{\text {a }}$ Câmara Criminal. Florianópolis - SC. Relator. Des. Jorge Schaefer Martins. Data de Julgamento em 27/02/2014. Disponível em: http://busca.tjsc.jus. br/jurisprudencia/html.do?q=\&only ementa $=\&$ frase $=\& i d=A A A b m Q A A C A A G i-$ bIAAX\&categoria=acordao. Acesso em: 20 maio 2019.

CUNHA, Rogério Sanches; PINTO, Ronaldo Batista. Violência doméstica: lei Maria da Penha comentada artigo por artigo. 6. ed. São Paulo: RT, 2015.

ELUF, Luiza Nagib. A paixão no banco dos réus. São Paulo: Saraiva, 2007.

GOMES, I. S. Feminicídios e possíveis respostas penais:dialogando com o feminismo e o direito penal. Gênero \& Direito, Periódico do Núcleo de Estudos e Pesquisas sobre Gênero e Direito Centro de Ciências Jurídicas, João Pessoa, n. 1, p. 193, 2015. Disponível em: http://www.periodicos.ufpb.br/ojs/index.php/ged/article/view/24472. Acesso em: 28 abr. 2019.

GOMES, L. F.; BIANCHINI, A. Feminicídio: entenda as questões controvertidas da lei 13.104/15. Instituto Avante Brasil, 2015. Disponível em: http://luizflaviogomes. com/feminicidio-entenda-as-questoes-controvertidas-da-lei-13-1042015/. Acesso em: 28 abr.2019.

MAGGIO, Vicente de Paula Rodrigues. Curso de direito penal. 2. ed. Salvador: Juspodivm, 2015.

MIRABETE, Júlio Fabbrini. Código de processo penal interpretado. 8. ed. São Paulo: Atlas, 2001.

NUCCI, Guilherme de Souza. Código de processo penal comentado. 11. ed. São Paulo:Revista dos Tribunais, 2013.

NUCCI, Renan. Causa da violência contra mulheres é motivo fútil. Campo Grande, 
2014. Disponível em: https://www.geledes.org.br/causa-da-violencia-contra-mulheres-e-motivo-futil-afirma-promotora/. Acesso em: 19 abr. 2019.

PIRES, Amom Albernaz. A natureza objetiva da qualificadora do feminicídio e sua quesitação no tribunal do júri. 2015. Disponível em: https://amomalbernaz.jusbrasil. com.br/artigos/172762972/a-natureza-objetiva-da-qualificadora-do-feminicidio-e-sua-quesitacao-no-tribunal-do-juri. Acesso em: 28 abr. 2019.

SANCHES, Rogério. BIANCHINI, Alice. Lei do feminicídio: breves comentários. Disponível em: https://rogeriosanches2.jusbrasil.com.br/artigos/172946388/ lei-do-feminicidio-breves-comentarios?ref=topic_feed. Acesso em: 28 abr. 2019.

TOMAZ, Kleber. Nem todo assassinato de mulher por homem é feminicídio, diz delegado. São Paulo, 2017. Disponível em: https:/g1.globo.com/sao-paulo/noticia/ nem-todo-assassinato-de-mulher-por-homem-e-feminicidio-diz-delegado.ghtml. Acesso em: 28 abr. 2019.

Recebido em: 30/04/2019

Aprovado em: 04/06/2019 